\title{
HAEMATOLOGICAL PROFILE DERANGEMENTS IN PATIENTS DUE TO NON-RESISTANT AND RESISTANT TYPHOID FEVER
}

\author{
Sunila Tashfeen, Naveed Asif*, Muhammad Farooq** \\ Army Medical College/National University of Medical Sciences (NUMS) Rawalpindi Pakistan, *Combined Military Hospital Quetta/National University of \\ Medical Sciences (NUMS) Pakistan, ${ }^{* *}$ Islamic International Medical College, Rawalpindi Pakistan
}

\begin{abstract}
Objective: To assess and compare the frequency of haematological parameter derangements in patients due to non-resistant and extended drug resistant (XDR) typhoid fever.

Study Design: Comparative cross-sectional study.

Place and Duration of Study: Pathology Department of Combined Military Hospital Quetta, from Jan to Dec 2019.

Methodology: A total number of 172 blood culture Salmonella positive patients irrespective of age and gender were included in this study. Salmonella strains were isolated and grouped further according to their drug sensitivity, $3 \mathrm{ml}$ venous blood was collected from these patients in Ethylene diamine tetra acetic acid container and blood complete count was done by semiautomated haematology analyser XP-100.

Results: There were 126 (73\%) males and $46(27 \%)$ females with mean age of $17.5 \pm 10.3$ years. Out of 172 subjects, $106(61.6 \%)$ had non-resistant typhoid and rest $66(38.4 \%)$ were diagnosed with extended drug resistant typhoid. We compared anaemia, leucopenia and thrombocytopenia between two groups and found anaemia statistically significant with the $p$-value of 0.001 .

Conclusion: This study has documented that changes in haematological parameters are significant in typhoid fever and early patients diagnosis, management and disease course can be monitored with them. Patients with significant anaemia and not responding to first line therapy should be considered as a case of extended drug resistant (XDR) salmonella.
\end{abstract}

Keywords: Extended drug resistant typhoid, Haematological parameters, Salmonella typhi.

How to Cite This Article: Tashfeen S, Asif N, Farooq M. Haematological Profile Derangements in Patients Due to Non-Resistant and Resistant Typhoid Fever. Pak Armed Forces Med J 2021; 71(5): 1615-1618. doi: https://doi.org/10.51253/pafmj.v71i5.4359

This is an Open Access article distributed under the terms of the Creative Commons Attribution License (https://creativecommons.org/licenses/by-nc/4.0/), which permits unrestricted use, distribution, and reproduction in any medium, provided the original work is properly cited.

\section{INTRODUCTION}

Typhoid fever is a common health problem in many countries and is still a major health hazard in developing parts of world, with an estimated annual incidence between 9.9 and 24.2 million cases. ${ }^{1}$ Current studies estimate that number of typhoid fever cases in Pakistan is second highest among five typhoid endemic Asian countries. ${ }^{2}$ Typhoid fever is caused by Salmonella Enterica, a gram-negative rod that invades human body through small intestines and colonies in reticuloendothelial system and later it enters in to the blood stream. ${ }^{3}$ Few cases may become a chronic carrier as bacteria colonize the gall bladder. Patients usually present with prolonged fever, headache, loss of appetite, abdominal pain and nausea. If left untreated complications may develop like intestinal perforation and neurological involvement. ${ }^{4}$

The prevalence and incidence of gastrointestinal diseases like typhoid fever markedly differs between developed and developing countries because of poor

Correspondence: Dr Sunila Tashfeen, Classified Pathologist, Army Medical College, Abid Majeed Road, Rawalpindi Pakistan

Received: 28 May 2020; revision received: 20 Jul 2020; accepted: 23 Jul 2020 sanitation, hygiene, impure water, food contamination, wide spread illiteracy and poverty in the developing world. Incidence can be substantially reduced by providing clean water and food to the population. ${ }^{5}$ It is the commonest water borne infection, which affects frequently young adults and children. ${ }^{6}$ Typhoid accounts for a large proportion of acute febrile illnesses and is a common cause of hospital admissions especially in younger age group. With the advent of chloramphenicol in 1948, many worries were ameliorated, regarding reduction of duration of illness and case fatality rate of typhoid fever. ${ }^{7}$

Till recent past chloramphenicol along-with ampicillin, amoxycillin and co-trimoxazole had been the traditional drugs for effective management of typhoid fever and most of the patients could be effectively managed by administration of one or two of these traditional drugs. However, in the recent years major concern is the emergence of multi drug resistant strains of salmonella typhi in many parts of the world, including Pakistan, which is threatening to become a therapeutic challenge. ${ }^{8}$ These strains are resistant to all traditional drugs like chloramphenicol, ampicillin, amoxycillin, co-trimoxazole and third generation cephalosporins. 
Only treatment option available for these resistant cases is Meropenem and Azithromycin. ${ }^{9}$ Rapid and accurate diagnoses coupled with appropriate antimicrobial therapy are of utmost importance in order to prevent mortality, morbidity and dreadful complications like intestinal perforation and haemorrhage. The incidence of extended drug resistant (XDR) Salmonella is on the rise and present study was designed with an aim to evaluate the significance and comparison of haematological changes in Non-resistant and Extended drug resistant (XDR) typhoid fever. Typhoid fever is associated with haematological parameters alterations like unicytopenia, bicytopenia and pancytopenia. Many studies had been done locally as well as at international level to show this association but none had compare the haematological values between selected two groups.

Study had been designed to assess and compare variations in haematological pattern in patients of drug resistant and non-drug resistant typhoid fever. These haematological parameters if significant can be used in early diagnosis and differentiation of resistant and non-resistant cases.

\section{METHODOLOGY}

This comparative cross-sectional study was conducted at Pathology department of Combined Military Hospital Quetta after approval from Institutional Review Board (Certificate No. CMH-QTA-IRB/025 Dated 6 ${ }^{\text {th }}$ March 2019) from January to December 2019. Patients admitted to medical wards of Combined Military Hospital Quetta were recruited.

Inclusion Criteria: Patients with history of fever and other symptoms and signs leading to the suspicion of typhoid fever were included in this study irrespective of their age and gender.

Exclusion Criteria: All the culture negative cases were excluded.

Non-probability consecutive sampling technique was used. We took reference incidence of typhoid fever from a study conducted in Pakistan with reported 170/100,000 incidence of typhoid annually to calculate sample size. ${ }^{2}$

Culture positive enteric fever cases were selected for further scrutiny and segregated according to their drug resistance status into two groups' i.e. non-resistant typhoid fever and XDR typhoid fever. Drug sensitive typhoid cases were caused by salmonella typhi or paratyphi which were sensitive to first line drug which include chloramphenicol, ampicillin, Trimethoprim- sulfamethoxazole and third generation cephalosporins, with or without resistance to second line drugs. XDR Typhoid cases were caused by Salmonella strains which were resistant to all the recommended antibiotics for typhoid fever. From these selected cases, $3 \mathrm{ml}$ venous blood was collected in EDTA container and mixed gently to ensure anticoagulation. Blood complete count was done by semi-automated haematology analyser XP-100 with appropriate quality control. Peripheral films were examined to exclude platelet clumping and red cell agglutination. Informed consents were taken from the subjects prior to sample collection.

Statistical analysis was done by SPSS version 26 . The study was designed to include demographic data like age and gender along with main focus on haematological parameters i.e. haemoglobin $(\mathrm{Hb})$, total leucocyte count (TLC) and platelet count. Cytopenias were taken as $\mathrm{Hb}$ less than $13 \mathrm{~g} / \mathrm{dl}$ in males and $12 \mathrm{~g} / \mathrm{dl}$ in females, TLC less than $4 \times 10^{9} / 1$ and platelet count less than $150 \times 10^{9} / 1$ as notable variable. ${ }^{10}$ These variables were compared and Chi square test was applied to non-resistant and XDR typhoid cases and $p$-value $<0.05$ was considered significant.

\section{RESULTS}

A total of 172 subjects were enrolled in the study, out of the 172 cases, $106(61.6 \%)$ had non-resistant typhoid fever and rest 66 (38.4\%) were diagnosed with XDR Typhoid fever. Salmonella typhi were found positive in $166(73 \%)$ cases and the remaining 6 cases $(27 \%)$ were caused by salmonella paratyphi A. salmonella paratyphi B was not isolated in any case. It was observed from the study of culture sensitivity reports that only salmonella typhi showed resistance to various antibiotics while none of the salmonella paratyphi A belong to XDR Typhoid group.

Overall males were $126(73 \%)$ and $46(27 \%)$ were females. Further gender distribution of patients considering non-resistant and XDR typhoid cases was exhibited in Table-I.

Table-I: Gender distribution in study groups.

\begin{tabular}{l|c|c}
\hline & $\begin{array}{c}\text { Non-Resistant } \\
\text { Typhoid }\end{array}$ & $\begin{array}{c}\text { Extended Drug } \\
\text { Resistant-Typhoid }\end{array}$ \\
\hline Male & $80(75 \%)$ & $46(75 \%)$ \\
\hline Female & $26(25 \%)$ & $20(30 \%)$ \\
\hline
\end{tabular}

Mean age of patients was $17.5 \pm 10.3$ years range from 5 days to 45 years. Most of the patients presented in third decade of life that is $62(36.0 \%)$ followed by $<10$ years of age. Age wise distribution of patients was displayed in Figure. 


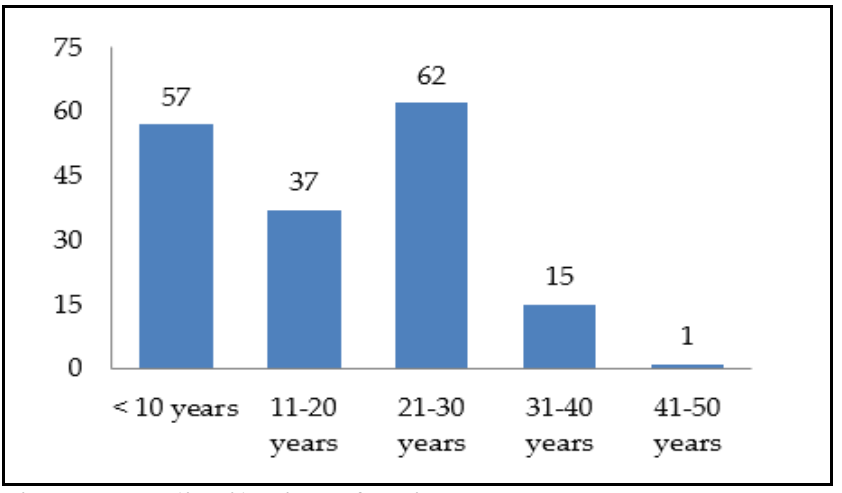

Figure: Age distribution of patients.

The mean TLC in the enteric group was $6.54 \pm 2.8$ x $10^{9} / 1$. Minimum TLC was $1.1 \times 10^{9} / 1$ and maximum was $23.2 \times 10^{9} / 1$. The haemoglobin range in Enteric patients was from 6.2 to $17.1 \mathrm{~g} / \mathrm{dl}$ with mean of $12.6 \pm$ $2.19 \mathrm{~g} / \mathrm{dl}$ and mean platelet count was $217 \pm 113 \times 10^{9}$ / 1 with minimum platelet count of $20 \times 10^{9} / 1$ and maximum $830 \times 10^{9} / 1$. Haematological results of the nondrug resistant and XDR typhoid isolates were compared. There was no significant difference in the leucopenia and thrombocytopenia $(p>0.05)$ whereas there was statistically significant association regarding anaemia between two groups with $(p=0.001)$ (Table-II).

Table-II: Comparison of haematological parameters of patients suffering from non-resistant and extended drug resistant Typhoid.

\begin{tabular}{|c|c|c|c|}
\hline Parameters & \multicolumn{2}{|c|}{ Frequency (\%) } & \multirow{2}{*}{$\begin{array}{c}p- \\
\text { value }\end{array}$} \\
\hline Total Leucocyte Count & Leucopenia & Normal & \\
\hline Non-Resistant Typhoid & $16(15)$ & $90(85)$ & \multirow[b]{2}{*}{0.379} \\
\hline $\begin{array}{l}\text { Extended Drug- } \\
\text { Resistant Typhoid }\end{array}$ & $8(12)$ & $58(88)$ & \\
\hline Haemoglobin & Anaemia & Normal & \\
\hline Non-Resistant Typhoid & $40(37.7)$ & $66(62.3)$ & \multirow[b]{2}{*}{0.001} \\
\hline $\begin{array}{l}\text { Extended Drug- } \\
\text { Resistant Typhoid }\end{array}$ & $42(63.6)$ & $24(36.4)$ & \\
\hline Platelet Count & Thrombocytopenia & Normal & \\
\hline Non-Resistant Typhoid & $28(26.4)$ & $78(73.6)$ & \multirow[b]{2}{*}{0.157} \\
\hline $\begin{array}{l}\text { Extended Drug- } \\
\text { Resistant Typhoid }\end{array}$ & $23(35)$ & $43(65)$ & \\
\hline
\end{tabular}

\section{DISCUSSION}

Enteric fever is a life threatening illness that affects $>21$ million people in the developing world and emergence of drug resistant Salmonella Typhi has become a prime health concern in Pakistan. ${ }^{11,12}$ Pathophysiology of typhoid fever is complex and begins with a asymptomatic phase of 7-14 days during which bacteria spreads throughout the reticuloendothelial tissue followed by a symptomatic phase with fever and finally bacteraemia. During third week patient may develop complications like intestinal bleeding, perfo- ration and encephalopathy if not treated appropriately.13,14 XDR Salmonella cases early identification is of great value, as they will not respond to the all the recommended antibiotics and patient may progress to complications of enteric fever. ${ }^{15}$ Limited therapeutic options are available for XDR Typhoid cases and importance of differentiating Non-resistant salmonella from XDR Salmonella cannot be disregarded and more over haematological parameters are deranged in typhoid and can guide about patient response to treatment. 16,17

The principal observation of our study was the comparison of haematological results and cytopenias of Non-resistant and XDR Typhoid cases and results showed that anaemia was the most common finding in both groups with over all percentage of $47.6 \%$. The results of our study are in accordance with the results of local and international studies. Dhillon et al. reported anaemia in $47.8 \%$ of cases which is comparable to our study. ${ }^{18}$ However anaemia showed statistical significant association between Non-resistant and XDR Typhoid cases with frequency of $37.7 \%$ and $63.6 \%$ respectively and significant $(p=0.001)$. Presence of anaemia in typhoid fever was due to maturational arrest of cell lines but this unusual high frequency in XDR Typhoid leads to the suspicions of association with intestinal bleeding and haemorrhages along with glaring effect on bone marrow. Bone marrow examination was done in 4 cases of XDR Typhoid and there was marked haemophagocytosis in bone marrow.

Leucopenia was observed in $24(14 \%)$ cases where as leucocytosis was seen in $11(6.3 \%)$ cases. Rest of the patients had normal white blood cell count. These results did not agree with study of Shilpa et al, in which only leucocytosis was observed in $22.41 \%$ cases and none presented with leucopenia. ${ }^{5}$ However, Kakaria et al, reported leucopenia in $10 \%$ of their patients which is comparable to our results. ${ }^{19}$ Leucopenia incidence was not significant between non-resistant and XDR Typhoid group $(p=0.379)$.

Thrombocytopenia was present in 51 (29.6\%) cases which were higher from reported results of Shilpa et al, ie $17.24 \%$ whereas it is lower from Shrivastava et al, which were $39.7 \% .5,20$ Our results were comparable to other studies but association between the two groups was not significant $(p=0.157)$.

The results of our study suggest that haematological parameters were deranged notably in enteric fever and XDR Salmonella. Cytopenias were present in both groups however, anaemia was more pronounced 
as compared to leucopenia and thrombocytopenia in XDR typhoid group. Accurate identification of drug resistant species is useful in defining appropriate therapy and simple blood counts can give clue to the patient condition, drug resistance, development of complication and response to therapy. The primary purpose of all diagnostic tests is to contribute to improvement in the health of patients. Emergence of increasing incidence of drug resistant strains is an alarming issue and a real challenge for physicians and early identification of these cases is vital to shorten their hospital stay.

\section{LIMITATION OF STUDY}

There is marked association of anaemia with XDR Typhoid but further investigations should be done to delineate its cause. Further studies are required to analyze blood indices, nutritional values and stool for occult blood

\section{CONCLUSION}

This study has documented that changes in haematological parameters are significant in typhoid fever and early patient's diagnosis, management and disease course can be monitored with them. Deranged haematological profile with significant anaemia and patients not responding to first line therapy should be considered for aggressive therapy and scrutinize for complications.

\section{Conflict of Interest: None.}

\section{Authors' Contribution}

ST: Conceived, designed, manuscript writing, data collection, NA: Data analysis, MF: Manuscript revision.

\section{REFERENCES}

1. Marina A, Joshua LW, Forrest WC, Daniel MW, Esra K, Gi Deok $\mathrm{P}$, et al. The burden of typhoid fever in low and middle income: A meta regression approach. PLoS Negl Trop Dis 2017; 11(2): e0005376.

2. Taranum RS, Safia B, Muhammad AM, Sobiya MA. High prevalence of typhoidal Salmonella enterica serovars excreting food handlers in Karachi-Pakistan: a probable factor for regional typhoid endemicity. J Health Popul Nutr 2015; 33(2): 27-32.

3. Bhan MK, Bahl R, Bhatnagar S. Typhoid and paratyphoid fever. Lancet 2005; 366(3): 749-762.

4. Dougan G, Baker S. Salmonella enterica serovar Typhi and the pathogenesis of typhoid fever. Annu Rev Microbiol 2014; 68(1): 317-336.

5. Shilpa VU, Syeda HK and Mandakini BT. Haematological profile in typhoid fever. Ind J Pathol Oncol 2017; 4(2): 263-265.

6. Fauci AS, Loscalzo J, Kasper DL, Hauser SL, Longo DL, Jameson JL. Harrison's principles of internal medicine 18th ed. New York:
McGraw Hill; 2012, [Internet] Available from: https://accessmedicine.mhmedical.com/book.aspx?bookID=2129

7. Obeagu EI. Changes in some haematological parameters in typhoid patients attending University Health Sevices Department of Michael Okpara University Agriculture, Nigeria. Int J Curr Microbiol App Sci 2014; 3(1): 670-674.

8. WHO. Typhoid fever-Islamic Republic of Pakistan. 2018 [Internet] Available at: http://www.who.int/csr/don/27december-2018-typhoid-pakistan/en/ (Accessed on April 1 2019)

9. Yousafzai MT, Hamar FN, Shakoor S. Ceftriaxone resistant Salmonella type outbreak in Hyderabad city of Sindh, Pakistan: high time for the introduction of typhoid conjugate vaccine. Clin Infect Dis 2019; 68(1): S16-S21.

10. Drew P, Trevorr B, Inderjeet D, Johannes DV. Oxford handbook of Clinical Haematology. Fourth Edition. Oxford University Press; 2015, [Internet] Available from: https://oxfordmedicine. com/view/10.1093/med/9780199683307.001.0001/med9780199683307

11. Saeed N, Usman M, Khan EA. An overview of extensively DrugResistant Salmonella Typhi from a Tertiary care hospital in Pakistan. Cureus 2019; 11(9): 1-8.

12. Klemm EJ, Shakoor S. Emergence of an extensively drug-resistant Salmonella enterica serover Typhi clone harboring a promiscuous plasmid encoding resistance to fluoroquinolone and third generation cephalosporins. mBio 2018; 9(1): e00105-e00118.

13. Edward TR, Jason A. Treatment and prevention of enteric (typhoid and paratyphoid) fever. 2019. [Internet] Available from: https://www.uptodate.com/contents/treatment-andprevention-of-enteric-typhoid- and-paratyphoid-fever. (Accessed on April 10, 2019)

14. Deen J, von Seidlein L, Andersen F, Elle N, White NJ, Lubell Y. Community-acquired bacterial bloodstream infections in developing countries in south and southeast Asia: a systematic review. Lancet Infect Dis 2012; 12(1): 480-487.

15. Crump JA, Sjölund-Karlsson M, Gordon MA, Parry CM. Epidemiology, clinical presentation, laboratory diagnosis, antimicrobial resistance and antimicrobial management of invasive salmonella infections. Clin Microbiol 2015; 28(4): 901-937.

16. Chris D. Study: XDR typhoid in Pakistan carries added resistance genes. 2018 [Internet] Available from: htttp://www. cidrap.umn.edu/ (Accessed on Feb 2, 2020)

17. Marks F, Von Kalckreuth V, Aaby P, Adu-sarkodie Y, Ahmed M, Tayeb E, et al. Articles Incidence of invasive salmonella disease in sub-Saharan Africa: a multicentre population-based surveillance study. Lancet Glob Health 2017; 5(2) :e310-e323.

18. Dhillon SPS, Neeraj L, Sehajpreet S, Vijay G, Tanushree J, Narinder S. To study haematological profile of Enteric fever patients. Int J Curr Res Med Sci 2017; 3(7): 24-29.

19. Kakaria A, Asgaonkar D, Narkhede M. Clinical profile of enteric fever: a prospective study of 50 enteric fever patients. Int J Res Med Sci 2014; 2(1): 1620-1625.

20. Shrivastava K, Vahikar S, Mishra V. Haematological profile in typhoid fever. Trop J Path Micro 2015; 1(1): 16-20. 